\title{
Assessing how Physical Education Faculty Behaviors Affect College Student Perceptions of Them as Health Instructors: Do we Practice What we Teach?
}

\author{
John Lothes II, LPA, Ed.D. \\ University of North Carolina Wilmington
}

\begin{abstract}
Background: While there is a large body of evidence on faculty as role models, there is scant research on physical education faculty and how their behaviors may be reflected and internalized in student health perceptions.

Aim: To determine the impact of physical education faculty health behaviors on student perceptions.

Method: Surveys were administered among college students enrolled in a number of Physical Education (PED 101) courses at a university in the southeast United States. Different vignettes (healthy versus unhealthy behaviors) were provided describing scenarios where students may observe their physical education faculty both on and off campus. Scenarios were assessed to examine how there may be an effect on the student's perception as either favorable or unfavorable of faculty as a health instructor.

Results: Both salient behaviors (e.g., seeing faculty exercising on campus or drinking water during class) and non-salient cues (e.g., having a grocery cart full of health or unhealthy foods at the store) both play a role in students' perceptions.

Conclusion: Physical Education faculty must be aware that behaviors they engage in both in the classroom and out of the classroom may shape how students perceive them.
\end{abstract}

Submitted 18 July 2019: accepted 9 September 2019

Keywords: health education, college student health, faculty health behaviors, model of health behaviors

Faculty have functioned as role models for students since the inception of the academe. Different studies have examined students' perceptions of faculty as teachers and mentors (Frick, Chadba, Watson, Wang, \& Green, 2009; Uttl, White, \& Gonzalez, 2017). While writing on health instructors acting as role models has been around for over half a century (McCloy, 1940), to date, there is scant to no evidence on how physical education faculty's personal health behaviors play a role in student perceptions of them as health instructors. This idea should be of special interest to health educators since they are often the first line of knowledge about health and well-being in college student learning.

Albert Bandura's (1961) famous Bobo doll experiment on observational learning, or social learning, later coined social cognitive theory (1986), illustrated how adults act as models for children's behaviors. People are more likely to imitate individuals that they look up to. Bandura's research shows that children tend to behave more like people that they admire or perceive as similar to themselves. According to Bandura (1977), there are four mediational processes at work in social learning theory: (1) Attention - the extent to which we are exposed to or notice the behavior; (2) Retention - how well the behavior is remembered; (3) Reproduction - the ability to perform the behavior that was 
modeled; and (4) Motivation - the will to perform the behavior. Examining physical education faculty behaviors through the social learning model can help facilitate effective experiential learning processes beyond the scope of the classroom.

Meta-analysis of social learning theory has shown that social learning currently still holds relevance to different theories and applications of human behavior (Pratt et. al., 2009) and health promoting behavior (Bandura, 2004). Brown and Adler (2008) believe that the understanding of content is constructed through two parts; the first being a social interaction about the content, especially with others (e.g., group projects, discussions in class, engagement with fellow students and faculty member). The second part consisting of the material being learned through a form of grounded academic interaction (e.g., information taught by an instructor). Generally speaking, social learning has been conceptualized as learning from others and it is the processes of interaction that leads to actions of change, either through learning as a group or learning as an individual within that social context (Blackmore, 2010). Hagel, Seely Brown and Davidson (2010) argue that the move from "push" to "pull" motivates an analysis that can be accessed by students at any point. This learning comes in both formal and informal settings, are sensitive to social relationships and allow for transferable learning and the development of dispositional skills.

Akers (2001) believes that acts are that reinforced, either by a reward process or by the avoidance of some form of discomfort are more likely to be repeated. Whereas acts that elicit some form of punishment are less likely to be repeated by an individual. Reinforcements can be physical in nature and can elicit bodily changes (e.g., exercise or eating). Akers argues that the most important reinforcers are social in nature (e.g., those coming from people that the individual looks up to). Behaviors that are observed from individuals that are looked up to are more likely to influence not only the other people's behaviors, but how they view that person.

Different avenues of research have been conducted on how faculty play a role as mentors in students' lives. However, there is scant research on how physical education faculty behaviors affect student's perceptions of them as health instructors. Behzadnia, Adachi, Deci and Mohammadzadeh (2018) examined how physical education teachers' interpersonal styles affected student's intentions to exercise after the class and student well-being. However, they did not examine how student's perceptions of the faculty behaviors may play a role in how students view them as creditable instructors. Researchers in other fields, such as engineering (Lambert, Terenzini, \& Lattuca, 2007) have shown that active learning activities and cooperative education experiences help increase student's experiences. Students in programs where the faculty were engaged in some form of professional development to improve themselves as educators showed a stronger influence on student outcomes than faculty that were not engaged in some form of professional development activity. The results from Lambert, Terenzini, and Lattuca (2007) study also found that one of the strongest predictors of student experiences consisted of a combination of in and out of classroom experiences.

Research on modeling behaviors by faculty has been conducted in medical schools (Treadwell \& Grobler, 2001) and nursing programs (Knox \& Morgan 1985; Lovric et al., 2014) for years. Lovric et al. (2014) found that first-year nursing students had significantly higher expectations of their clinical faculty, particularly in terms of teaching ability, while second-year students had significantly lower expectations, mainly for the personality styles of clinical faculty. After the students' clinical practice, overall clinical faculty competency evaluations were significantly lower for the first-year students, whereas the second and third-year students' evaluations of their clinical faculty were more representative of their expectations. 
To date, there is no research on how physical education faculty behaviors may impact students' perceptions. However, research has been conducted on the extent to which medical professionals are viewed as health experts by their patients (Puhl, Gold, Luedicke, \& DePierre, 2013). This notable gap in research is important to address for several reasons. First, faculty do act as role models in the student-faculty interaction (Komarraju, Msulkin, \& Bhattacharya, 2010). As physical education faculty, there is a need to be mindful that modeling of healthy (or unhealthy) behaviors for students (Bandura, 1977; Bandura, 1986) may be internalized and reflected in student behaviors. Some of these cues are more salient, such as drinking water in class or being seen exercising on campus, while others may not be as glaring, such as observed behaviors in the larger community (i.e., being seen out while intoxicated on the weekend or running into a student at the grocery store; Cox \& Orehovec, 2007). The degree to which these cues are perceived as relevant to overall health may vary based on level of importance to the student (Akers, 2001).

Research shows that health professionals who are of "normal weight" express more confidence in their weight management practices, perceive fewer barriers to weight management, have more positive outcome expectations, and have stronger role identity than health professionals who are overweight or obese (Zhu, Norman, \& While, 2011). Third, informal interactions with faculty that may occur outside of the classroom have shown effects on students' motivation beyond that of typical predictors of academic performance (Pascarella \& Terenzini, 2005).

Based on Cox and Orehovecs (2007) four major types of student-faculty interactions can have an effect on student's perceptions of health and well-being behaviors. Ranging from the most important interaction, being a "functional interaction," which addresses academic-related interactions outside of the classroom. The other types include some form of personal interaction about issues that are not related to academics, incidental contact which may occur in the community, and finally disengagement, where there is little interaction with the faculty inside the classroom and little to no interpersonal exchange.

There is a body of research on medical professionals and how patient's perceptions of them affect the health behaviors of their patients. The outcomes of this research have shown that overweight or obese patients are more likely to trust the opinions of physicians that are of "normal" weight. The results from this study also found that patients are more likely to adhere to their doctor's advice when it comes from "normal" weight range physicians than when it comes from those that are overweight or obese (Bleich, Bennett, Gudzune, \& Coope, 2012). Frank, Breyan, and Elon (2000) found that physicians who disclose their personal health, diet, and exercise habits are perceived as more believable, healthier, and more motivated by their patients compared to physicians who do not disclose their health behaviors. Furthermore, Smith and Leggat (2007) showed that personal health behaviors of physicians have been associated with patients' perceptions of their credibility. Hull, DiLalla, and Dorsey (2008) found that patients are less likely to listen to physicians that they perceive as unhealthy when they try to advise them about making healthy lifestyle choices and physicians are more likely diagnosis and to recommend treatments, than to educate patients that they perceive as overweight.

While prior research does not specifically address health instructors, it still provides a relevant frame of reference into understanding how students may perceive healthy versus unhealthy faculty and listen to or not listen to what is being taught. These results are relevant since physical education faculty are often seen as knowledgeable when it comes to health behaviors, like physicians. Since the current research on physical education faculty and perceptions of students is scant, examining these outcomes from the frame of how medical facilitators are perceived sets the precedent to start to understand how students may listen to or pay attention to their health instructors. If the physical 
education instructors are not behaving in ways that are consistent with what they are teaching, then this modeling may be counterproductive to any knowledge based information that they are trying to teach from an academic standpoint.

Understanding that two-thirds of American adults are either overweight or obese (Flegal, Carroll, Kit, \& Ogden, 2012), and that over a ten year period between 1998 - 2008 the number of states with young adults who were overweight or obese went from 1 to 39 (Centers for Disease Control and Prevention, 2009), it is imperative that physical education faculty serve as healthy role models for young adults. Further considering that many lasting adult behaviors are established in college (Sparling \& Snow, 2002), modeling healthy behaviors for college students is critical. As physical education faculty it is important to understand that they are laying the foundation for healthy lifestyle behaviors for their students.

\section{Purpose of Study}

The purpose of this study was to examine how the potential behaviors of Physical Education (PED 101) instructors may affect how students perceive them as credible health instructors. Students in PED 101 courses at a university in the southeastern part of the United States (IRB approval \#18-0115) were surveyed. Different variables were examined to determine if there were differences in perceptions of faculty health behaviors for this population. For example, the survey assessed how students observing their physical faculty drinking water, soft drinks, or diet soft drinks during class might affect these students' perceptions of their faculty as a health instructor. Survey questions also asked about behaviors (both healthy and unhealthy) that students may see faculty engaging in beyond the classroom. Such as if a student saw their physical education faculty exercising on campus or in the grocery store with a cart full of health food items versus seeing their physical education faculty smoking or intoxicated while out in public. This research was exploratory in nature; however, it was hypothesized that PED 101 faculty who engage in healthier behaviors would be viewed more positively by students as health instructors and health instructors that were seen engaging in unhealthy behaviors would be seen more negatively by the students.

\section{METHODS}

\section{Participants}

The PED 101 course consisted of two parts, there was a face to face activity lab and an online lecture component. Each activity lab class was a two credit course that met for an average of 50 minutes face to face two times a week for a face to face activity class with an instructor. The online learning assignments were consistent across all the PED 101 classes. The online class consisted of tutorials and assignments addressing different aspects of wellness. All faculty taught in the same department and college and positions ranged from full-time faculty to adjunct. All PED101 instructors either had an academic background qualifying them as a health instructor (e.g., graduate degrees in Exercise Science, Athletic Training). For some of the more specialized labs, such as Brazilian jujitsu and Aikido, adjuncts were required to teach these courses. Even for the specialized instruction the instructors had to produce some form of evidence to demonstrate that they had professional experience enough to teach this course (e.g., holding a rank of significance in their respective martial arts or yoga teacher training certifications). 
All students taking PED 101 (approximately 1,400 individuals) were emailed a survey link (December 2017; a full survey has been provided as Appendix A) to the study's anonymous online survey. There were 50 PED 101 courses offered as a lab component to a physical education class. These courses included general physical education classes (functional fitness), strength classes (weightlifting), martial arts classes (Aikido, self-defense, Brazilian jujitsu), movement/flow classes (swing dance), endurance (half marathon), and yoga. The PED 101 courses were a core requirement for graduation and taken by a mix of students ranging from freshman to senior level.

One hundred and fifty-five students (mean age $=20$ ) completed the online anonymous survey. This was approximately a $11 \%$ return rate for student surveys. Demographics were recorded for gender $(\mathrm{male}=39$, female $=$ 116 , other $=0$, Total $=155)$, for class rank $($ freshman $=56$, sophomore $=46$, junior $=32$, senior $=21$, total $=155)$, and class type (yoga $=38$, strength $=16$, martial arts $=31$, movement $/$ flow $=7$, endurance $=27$, and general $=36$, $N=155$ ). Data on specific course sections was not collected to keep student anonymity, for example there were multiple yoga and swimming courses offered as PED 101 classes, the survey asked which course students were in and did not collect section numbers to help maintain student anonymity, per suggestion of the IRB board. Courses were further categorized for analysis, for example Self Defense, Aikido and Brazilian jujitsu were compiled into a martial arts category. Examples of strength courses are Core and Strength or Weightlifting. Half-Marathon, Triathlon, Walking and Running courses were categorized as endurance courses. Examples of movement/flow classes consisted of Partner Free Dance and Salsa and examples of the general course category were classes that did not fit into the previous categories or may have fit multiple classifications such as Tennis, Adventure Recreation and Functional Fitness. These examples were not an all-inclusive list, but provided examples of the different types of courses that fit in each category selected for analysis.

\section{Measures}

Health Behaviors Perception Questionnaire. The survey (see Appendix A) was administered online and anonymously and no faculty were present when students were taking the survey. The survey took approximately ten minutes to complete. The survey requested demographic information such as gender, age, class rank, and which class the student was taking. The survey also consisted of 17 Likert style questions developed by the researcher where students' attitudes were expressed on a scale ranging from 1 (very negative) to 10 (very positive). There were no reverse scored questions for this survey. Higher scores reflected more positive views and lower scores reflected more negative views. The questions asked about different health-related characteristics such as instructor's weight (overweight, underweight, healthy weight) as well as various health-related behaviors: Seeing an instructor smoking outside of class, consumption of diet or non-diet soft drinks during class, drinking water during class, seeing an instructor exercising on campus or in the recreation center, seeing an instructor consuming alcohol at a restaurant or bar, seeing an instructor intoxicated, or finding out that their instructor uses marijuana. Other questions about diet and nutritional habits were asked as well, such as the healthy or unhealthy contents of their instructor's cart in the case of a run-in at the grocery store or the discovery that their instructor is vegetarian or eats a high-protein diet. The health instructor perception survey was found to be satisfactorily reliable (17 items; $\alpha=.78)$ for this study. The operational definition of a negative influence included a response score of 3, 2, or 1, a neutral effect score included a response of a 4, 5, 6, 7 and a positive influence was scored as 8,9 , or 10 . 


\section{Statistical Analysis}

Overall outcomes were examined to see if there were any surface levels trends that developed on how students may have perceived health behaviors. If this were the case we would not expect to see any significance between groups, as they would all show the same statistical representation.

To analyze the data, descriptive statistics were used to compute demographic variables. Analysis of variance (ANOVA) was conducted for each of the demographic variables (e.g., sex, class rank, and type of class) to analyze differences between groups. Effect size was not calculated as there was no intervention that happened during this study to examine size of effect of intervention. Pearson correlation coefficients was used to determine the relationship between the study variables. The level of significance was set at $p<.05$.

\section{RESULTS}

Tables 1 - 4 represent the overall outcomes of the scores for student perceptions of different behaviors and how students rated seeing physical education faculty engaged in either health related behaviors (e.g., exercising on campus or drinking water during class) versus seeing physical education faculty engage in unhealthy behaviors (e.g., smoking before class or being over or under weight). Class rank differences can be seen in Tables 5 - 8 .

\section{Overall Health Perception Outcomes}

A number of trends surfaced from these results (Figures 1 - 4). The assessments that behaviors such as being seen smoking ( $n=114,73.5 \%$ negative), as a clear indicator of negative health behavior as far as students' perceptions of physical education faculty. Other negatively viewed health behaviors included: being seen eating fast food $(n=45$, $29.0 \%$ negative), finding out their faculty uses marijuana $(n=58,50.4 \%$ negative), seeing their physical education faculty intoxicated while out $(n=56,48.7 \%$ negative), their physical education faculty being overweight $(n=49$, $31.6 \%$ negative), the physical education faculty being under weight ( $n=33,21.3 \%$ negative), the faculty drinking both diet ( $n=54,34.8 \%$ negative), and non-diet soda in class $(n=57,36.8 \%$ negative), and seeing their physical education faculty out at the grocery store with cart full of unhealthy food items ( $n=62,40 \%$ negative).

Positive trends present for student perceptions of physical education faculty included: Seeing their physical education faculty exercising on/off campus $(n=115,74.2 \%$ positive), the faculty member being at a healthy body weight $(n=81,52.3 \%$ positive), seeing their physical education faculty drink water in class $(n=81,52.3 \%$ positive), and seeing their physical education faculty at the grocery store with a cart full of healthy items $(n=111,71.6 \%$ positive), as being positively viewed. 


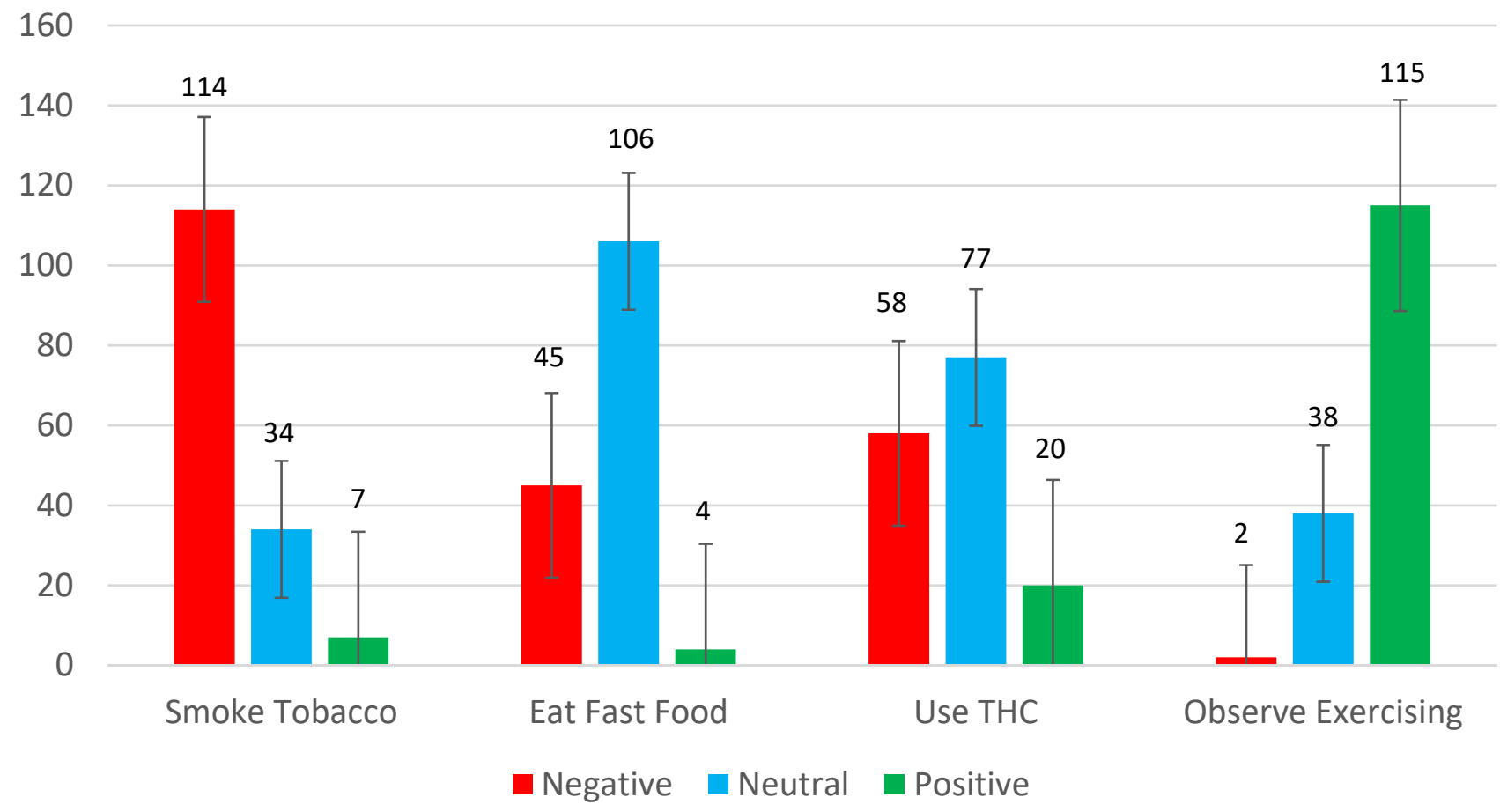

Figure 1. Overall health behaviors.

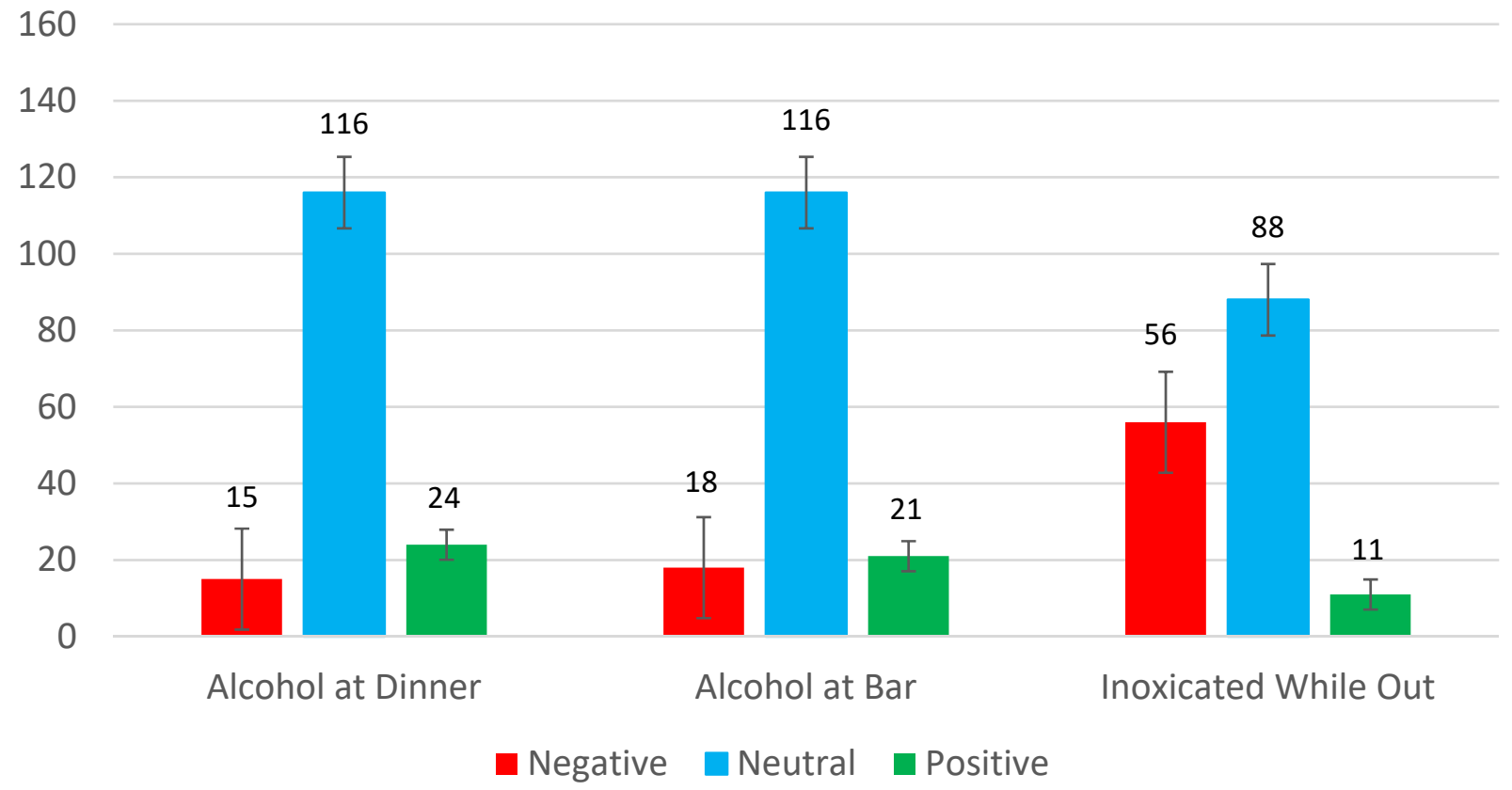

Figure 2. Overall alcohol behaviors. 


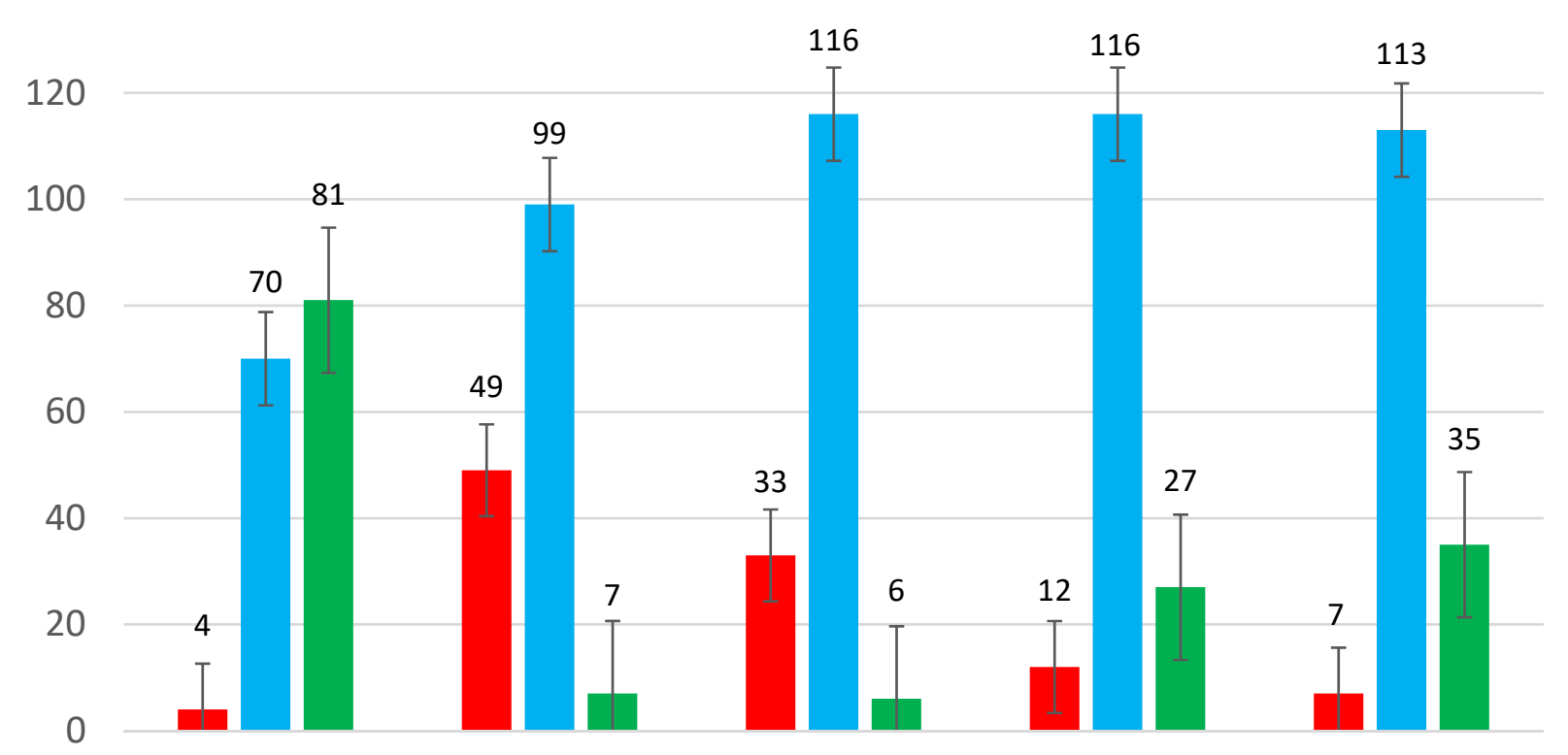

Healthy Weight Over Weight Under Weight Vegetarian Diet Protein Diet

negative Neutral $\square$ Positive

Figure 3. Overall eight and nutrition behaviors.

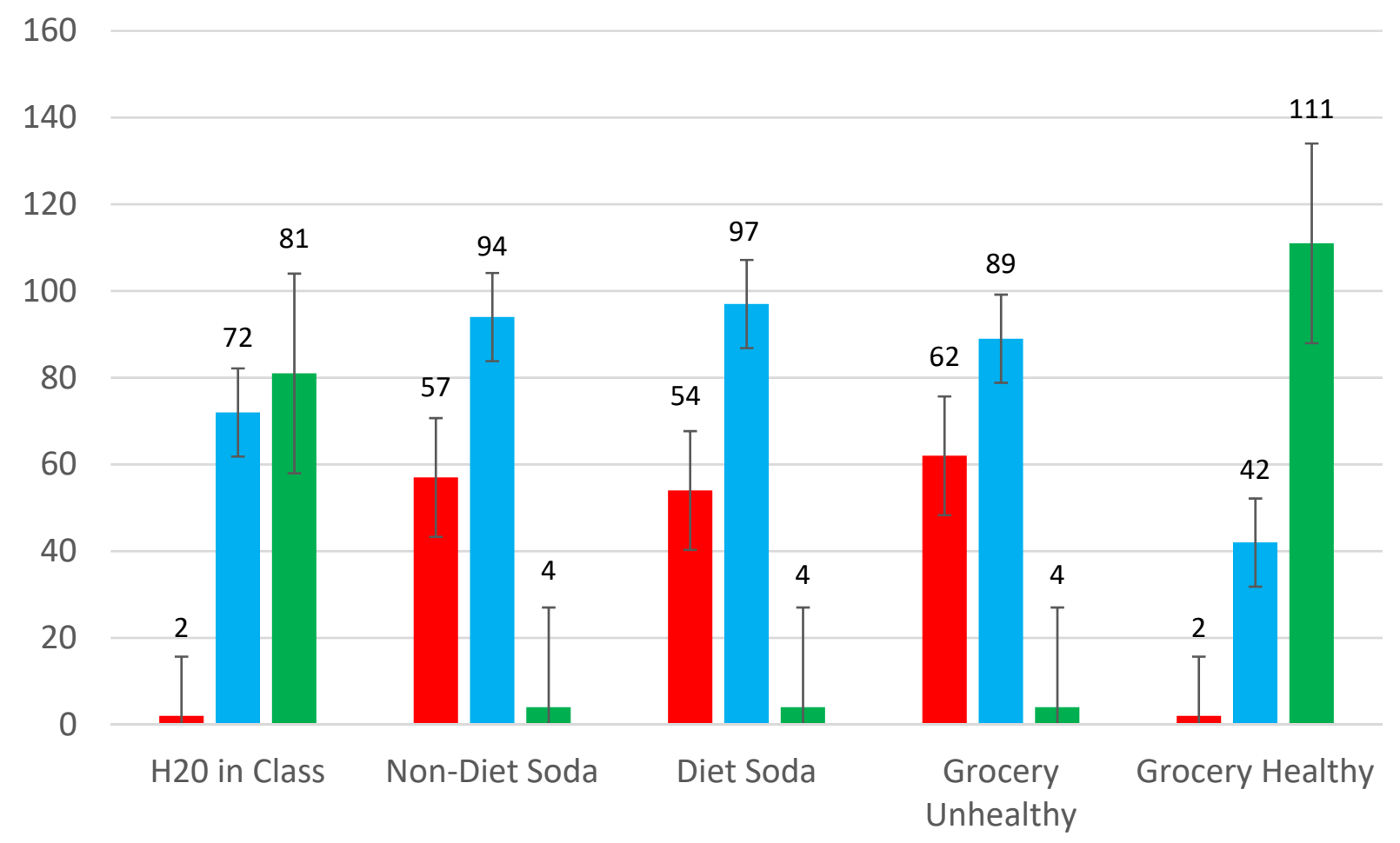

negative neutral Positive

Figure 4. Overall nutrition behaviors observed. 


\section{Gender}

For gender the only dimensions that showed a significant difference were the categories for vegetarian diet, where females reported significantly higher ratings than males $F(1,163)=7.80, p<.006, d=.49$, and protein diet, where males reported significantly higher ratings than females $F(1,163)=5.06, p<.03, d=.38$. For all other measures there were no significant differences.

\section{Class Rank}

For class rank (Figures 5 - 8) there was a significant difference in health perceptions between freshmen and sophomores about instructors' water consumption $F(1,160)=1.80, p<.02, d=.51$. Freshmen had significantly higher ratings for regarding their physical education faculty as being at a healthy weight than sophomores $F(4,160)=$ $1.86, p<.007, d=.52$.

For Tetrahydrocannabinol (THC) use, there was a significant difference in that seniors viewed using THC more positively than all other groups: Freshmen $F(4,160)=3.16, p<.003, d=.75$; sophomores $F(4,160)=3.16, p<.006$, $d=.73$; and juniors $F(4,160)=3.16, p<.007, d=.80$. As far as seeing their physical education instructor intoxicated, there was a significant difference between seniors and freshmen $F(4,160)=5.41, p<.001, d=1.02$, sophomores $\mathrm{F}(4$, $160)=5.41, p<.01, d=.60$, and juniors $F(4,160)=5.41, p<.009, d=.65$.

Concerning seeing their physical education faculty consume alcohol at a bar, seniors rated significantly higher than freshmen $F(4,160)=2.58, p<.003, d=.69$. With the exception of seniors rating significantly higher than freshmen for seeing physical education faculty having alcohol while out for dinner, there were no other significantly differing ratings between groups $F(4,160)=1.96, p<.02, d=.51$.

All other scales did not show significant differences between groups. 


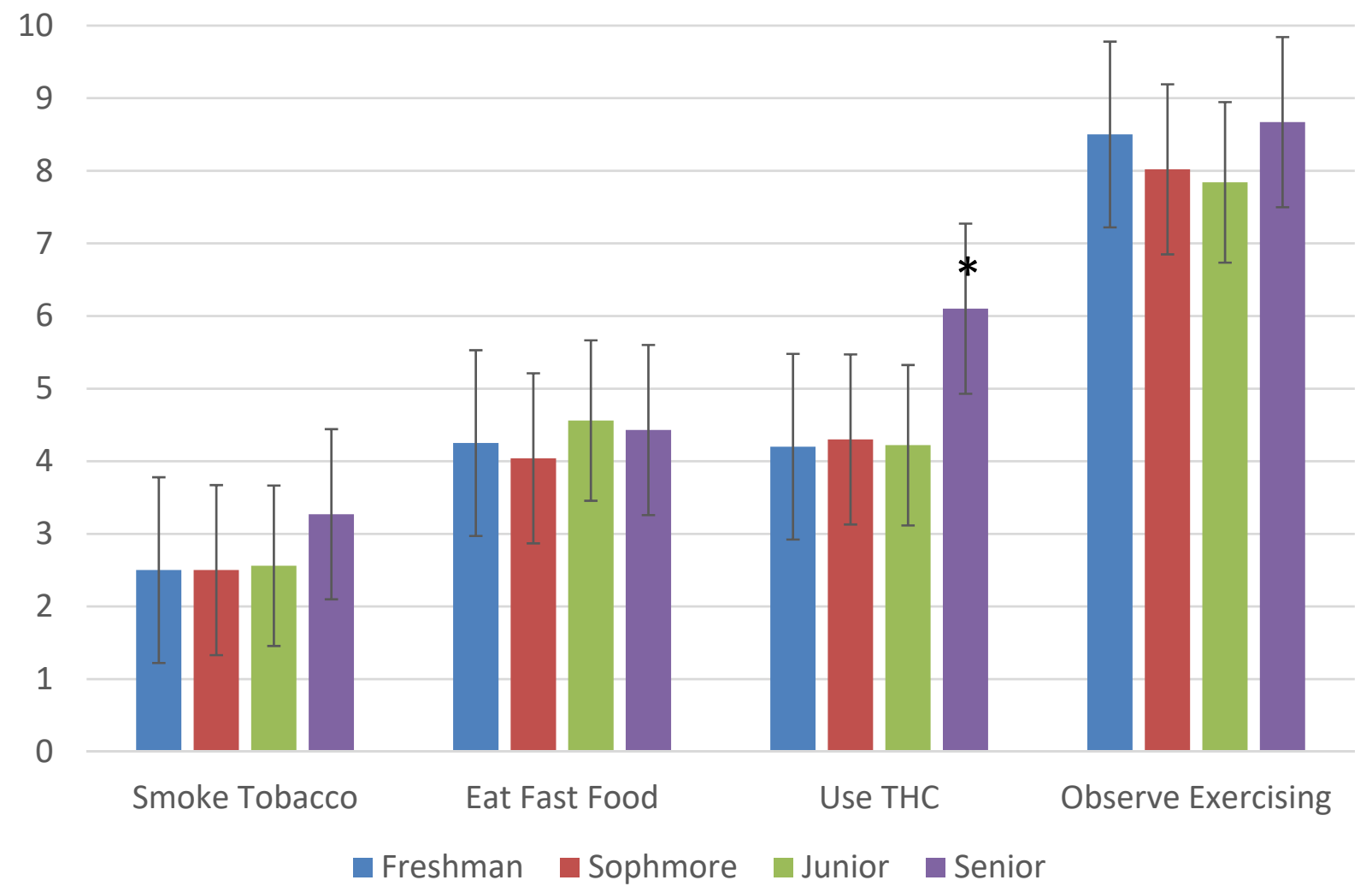

Figure 5. Health behaviors by class rank.

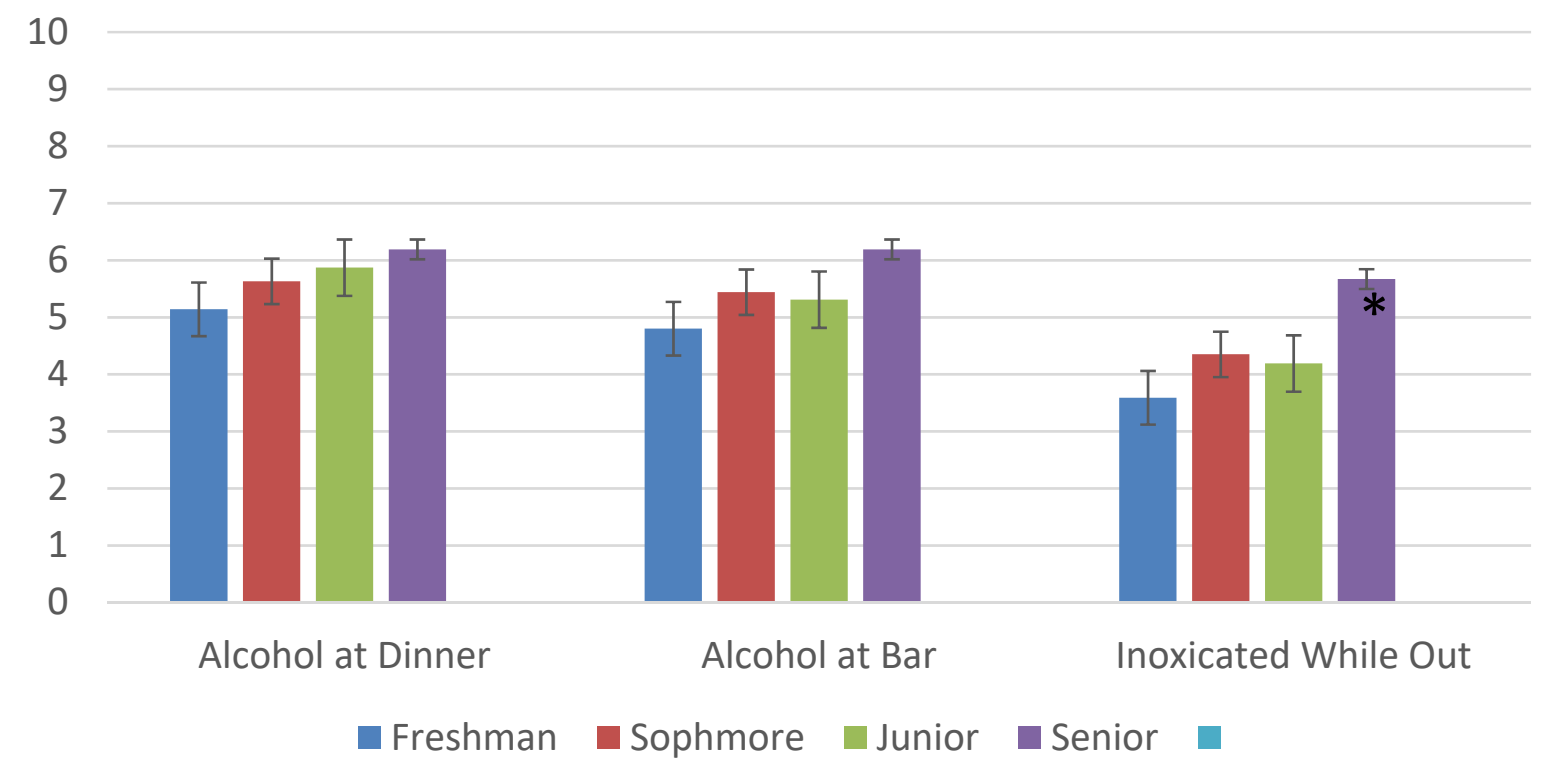

Figure 6. Alcohol behaviors by class rank. 


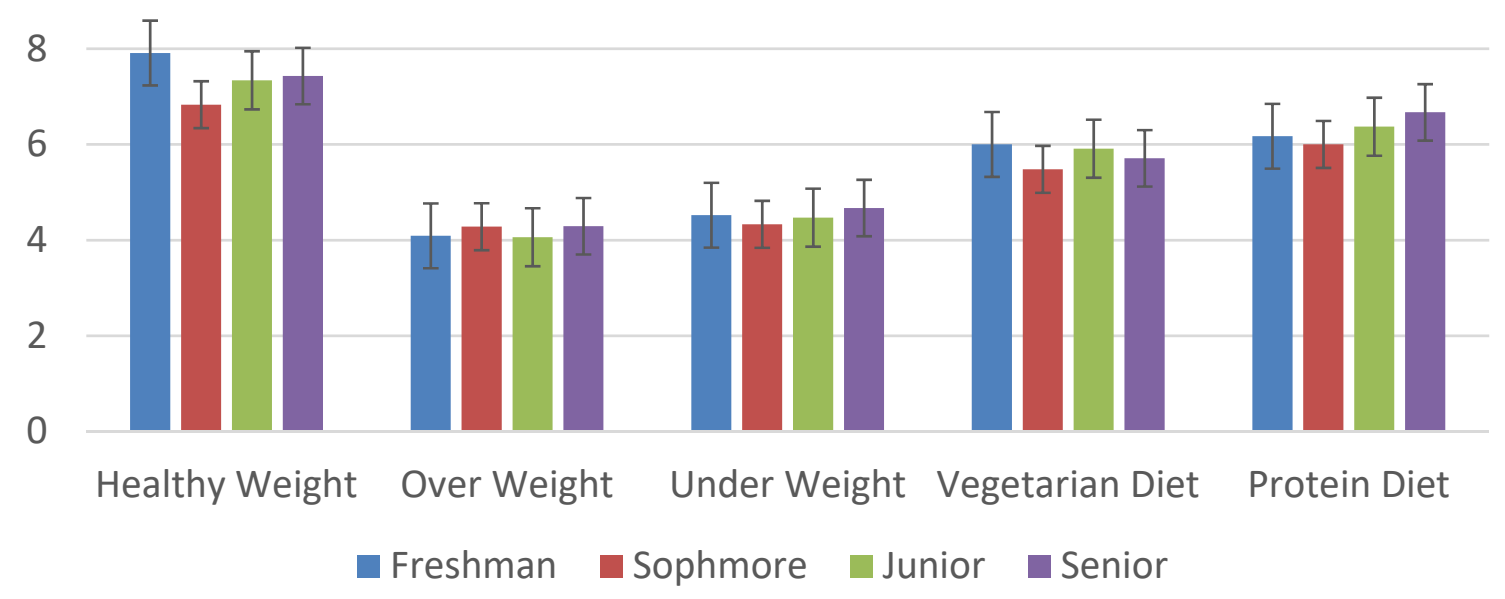

Figure 7. Weight and nutrition behaviors by class rank.

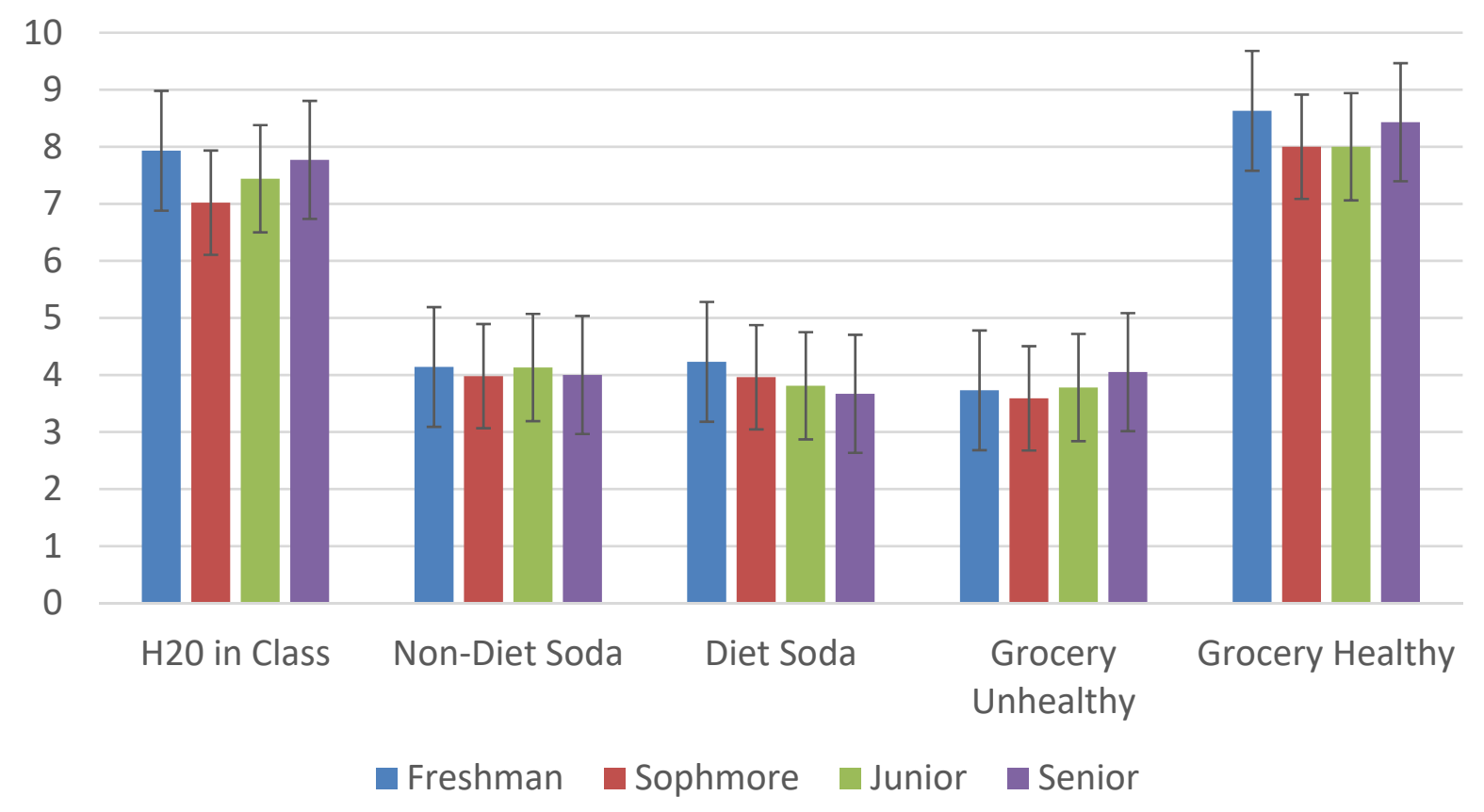

Figure 8. Nutrition behaviors by class rank.

\section{Class Type}

When examined by class type, yoga students rated underweight individuals significantly more negative than general students $F(5,149)=1.79, p<.02, d=.57$ and endurance students $F(5,149)=1.79, p<.03, d=.64$. For drinking soda (non-diet), the general class students rated faculty lower than martial arts students $F(5,149)=1.58, p<.03, d=$ .57 . 
For having alcohol at dinner, endurance students had significantly lower ratings than yoga students $F(5,149)=$ $3.10, p<.008, d=.67$, martial arts students $F(5,149)=3.10, p<.0007, d=.88$, and general students $F(5,149)=$ $3.10, p<.001, d=.80$. For students seeing their instructor consume alcohol at a bar, endurance students rated significantly lower than all other classes: $\operatorname{Yoga} F(5,149)=5.35, p<.001, d=89$; strength students $F(5,149)=5.35$, $p<.01, d=.79$; martial arts students $F(5,149)=5.35, p<.0001, d=1.21$; movement $/$ flow students $F(5,149)=5.35$, $p<.05, d=.70$; and general students $F(5,149)=5.35, p<.0001, d=1.10$.

All other ratings did not show significant differences between class types.

While some of these cues are more salient than others, it is important that physical education faculty be aware that their observed behaviors may have an influence on how their students perceive them as health instructors. Instructors must be mindful that their lifestyle choices in the larger community beyond campus—such behaviors as being intoxicated or smoking are likely to negatively impact how students perceive their physical education faculty instructors. While being seen by students picking out groceries at the local grocery store are also affecting to what degree they will be perceived as trusted health instructors by their students (Cardinal, 2001)

\section{DISCUSSION}

While the concept of being a healthy role model as a health educator has been around for a long time (McCloy, 1940), to our knowledge, this study is the first to assess how physical education faculty behaviors may affect students' perceptions of them as health instructors. These findings show that there are some trends that do exist within this data, for examples, there is a strong negative view toward instructors that are seen smoking and a strong positive view toward instructors that are of healthy weight. There was a slight positive trend for faculty that have a protein-rich diet, and a slight negative trend for faculty who were seen by students at the grocery store with a cart full of unhealthy items. There were strong positive trends for faculty that were observed drinking water in class, with healthy food items in their grocery cart at the store, and for those who were observed exercising on campus. These trends also held constant across gender, class rank, and the type of class that students were taking.

Even though instructors may not be aware of their influence on students there is research to show that studentfaculty interactions go beyond just academic performance (Decker, Dona, \& Christenson, 2007; Lambert et al., 2007). Darling-Hammond (2000) argues that while educational institutions have some influence on the performance of students, a substantial portion of that difference is attributed to the university instructors. Cardinal (2001) found that health instructors that are of healthy weight or below healthy weight expressed more favorable attitudes towards role modeling when compared to overweight or obese health instructors.

This study shows that while some behaviors appear more obviously related to personal health, such as smoking, even those subtler lifestyle choices (e.g., the contents of one's grocery cart) have a meaningful effect on how students perceive physical education faculty as negatively of positively. The findings of this study support and emphasize existing literature (Akers, 2001; Ince, 2008) that suggests that physical education faculty should be aware that their own behaviors are affecting how students see them both as health instructors and as viable role models for healthy behaviors. It is important for physical education instructors to recognize that not only are they role models for healthy lifestyle behaviors and that people paying attention to other's health habits (Puhl e al., 2013). As framed through Bandura's $(1977$; 1986) work, we need to be mindful that even if we are not aware of it, as physical education faculty 
we are constantly modeling health behavior habits for students (Cardinal, 2001; Pratt et. al., 2009; Sparling \& Snow, 2002).

Interestingly, the trends for instructors engaged in either healthy or unhealthy behaviors showed consistency across gender, class rank, and class type. This suggests that students may regard their instructors with more credibility when they are seen engaging in healthy behaviors on and off campus, and less credibility when they are seen engaging in unhealthy behaviors on and off campus. In light of these present findings, it seems warranted to examine whether these perceptions affect students' health behaviors in future studies. Behzadnia, Adachi, Deci, and Mohammadzadeh (2018) found that physical education instructors' interpersonal styles had an effect on student's intentions to exercise after class. However, they did not assess how students' perceptions of the health instructors' behaviors play a role in how students view them as creditable instructors.

Sparling and Snow's (2002) research found that many post-college behavior patterns are established in college. It is important for health instructors to be aware that their examples for students may have a lasting effect after college. Other research has shown that informal interactions with faculty members outside of the classroom have shown to have effects on students' motivation beyond that of typical predictors of academic performance (Pascarella \& Terenzini, 2005). Additionally, research on physicians health traits and patient outcomes have shown that healthy behaviors of the provider of information may either be well received or disregarded, based on the provider's health status (Bleich et al., 2012; Frank et al., 2000). Furthermore, Smith, and Leggat (2007) showed that personal health behaviors of physicians have been associated with patients' perceptions of their credibility. While, it is understood that physicians and physical education faculty are two different populations, the outcomes from these studies do provide insight into how health education professionals may be perceived by their students.

Findings from this study raise several additional questions that merit research attention. First, it is unclear whether the behaviors of health instructors actually have any effect on student health behaviors. It may be that these behaviors have an effect on how students perceive their health instructors, but not have any effect on the student's personal health choices. It will be informative and increasingly valuable for additional research to examine this issue. Second, it would be important to include faculty from other departments in order to see whether their behaviors may also have an effect on student health behavior patterns.

\section{LIMITATIONS}

Several limitations should be noted. Due to the nature of survey research, no causal relationships can be assumed. Given that participants' perceptions were assessed via self-report, it will be pertinent to examine whether model behaviors by faculty are actually having any effect on college students' health behaviors. Furthermore, this data sample was collected at one college campus and expanding this research to multiple campuses or regions would give us a clearer picture of how college students perceive their physical education faculty and what factors affect these perceptions.

\section{CONCLUSION}

In conclusion, this study suggests that physical education faculty who are seen smoking are regarded as less credible health instructors, while faculty who are seen engaging in healthy behaviors on and off campus are viewed as more authoritative. "Practice what [we] preach" is a relevant guideline for physical education faculty regarding how students 
will view them as health instructors. More research is needed to better understand how faculty health behaviors affect students' personal beliefs and behaviors surrounding health. Given that both students and instructors may struggle with health behaviors, we as physical education faculty must make a conscious effort to model effective health habits for the benefit of future generations. 


\section{REFERENCES}

Akers, R. L. (2001). "Social learning theory". In Explaining criminals and crime: Essays in contemporary criminological theory, Edited by: Paternoster, R. and Bachman, R. 192-210. Los Angeles, CA: Roxbury.

Bandura, A. Ross, D., \& Ross, S. A. (1961). Transmission of aggression through the imitation of aggressive models. Journal of Abnormal and Social Psychology, 63, 575-582. https://doi.org/10.1037/h0045925

Bandura, A. (2004). Health promotion by social cognitive means. Health Education \& Behavior. 31(2), 143-64. https://doi.org/10.1177/1090198104263660

Bandura, A. (1986). Social foundations of thought and action. Englewood Cliffs, NJ: Prentice Hall. https://doi.org/10.4135/9781446221129.n6

Bandura, A. (1977). Social learning theory. Englewood Cliffs, NJ: Prentice Hall.

Behzadnia, B., Adachi, P., Deci, E., \& Mohammadzadeh, H. (2018). Associations between students' perceptions of physical education teachers' interpersonal styles and students' wellness, knowledge, performance, and intentions to persist at physical activity: A self-determination theory approach. Psychology of Sport \& Exercise, 39, 10-19. https://doi.org/10.1016/j.psychsport.2018.07.003

Blackmore, C. (Ed.). (2010). Social learning systems and communities of practice. London, the United Kingdom: Springer. https://doi.org/10.1007/978-1-84996-133-2

Bleich, S., Bennett, W., Gudzune, K., \& Cooper, L. (2012). Impact of physician BMI on obesity care and beliefs. Obesity, 20, 999. https://doi.org/10.1038/oby.2011.402

Brown, S., \& Adler, R. (2008). Minds on fire: Open education, the long tail, and learning 2.0 EDUCAUSE Review, 43(1), 16-32.

Cardinal, B. (2001). Role modeling attitudes and physical activity and fitness promoting behaviors of HPERD professionals and pre-professionals. Research Quarterly for Exercise and Sport, 72(1), 84-90. https://doi.org/10.1080/02701367.2001.10608937

Centers for Disease Control and Prevention (2009). National Center for Chronic Disease Prevention \& Health Promotion Prevalence and trends data - Overweight and obesity. Behavioral Risk Factor and Surveillance System. Washington, D.C.: U.S. Department of Health and Human Services.

Cox, B. E., \& Orehovec, E. (2007). Faculty-student interaction outside the classroom: A typology from a residential college. The Review of Higher Education, 30(4), 343-362. https://doi.org/10.1353/rhe.2007.0033

Darling-Hammond, L. (2000). Teacher quality and student achievement. Education Policy Analysis Archives, 8(1), 4563. https://doi.org/10.14507/epaa.v8n1.2000

Decker, M. D., Dona P. D., \& Christenson S. L. (2007). Behaviorally at risk African American students: The importance of student-teacher relationships for student outcomes. Journal of School Psychology, 45, 83-109. https://doi.org/10.1016/j.jsp.2006.09.004 
Flegal, K.M., Carroll, M.D., Kit, B.K., \& Ogden, C.L. (2012). Prevalence of obesity and trends in the distribution of body mass index among US adults, 1999-2010. Journal of the American Medical Association, 307, E1-E7. https://doi.org/10.1001/jama.2012.39

Frank, E., Breyan, J., \& Elon, L. (2000). Physician disclosure of healthy personal behaviors improves credibility and ability to motivate. Archives of Family Medicine, 9(3), 287-90. https://doi.org/10.1001/archfami.9.3.287

Frick, T., Chadba, R., Watson, C., Wang, Y., \& Green, P. (2009). College student perceptions of teaching and learning quality. Educational Technology Research \& Development, 57, 705-720. https://doi.org/10.1007/s11423007-9079-9

Hagel, J., Seely Brown, J., \& Davison, L. (2010). The power of pull. New York: Basic Books.

Hull, S., DiLalla, P., \& Dorsey, J. (2008). Prevalence of health related behaviors among physicians and medical trainees. Academic Psychiatry, 32, 31-38. https://doi.org/10.1176/appi.ap.32.1.31

Ince, M. L. (2008). Use of a social cognitive theory-based physical-activity intervention on health-promoting behaviors of university students. Perceptual and Motor Skills, 107, 833-836.

Knox, J., \& Mogan, J. (1985). Important clinical teacher behaivors as percieved by university nursing faculty, students and graduates. Journal of Advanced Nursing, 10, 25-30. https://doi.org/10.1111/j.13652648.1985.tb00488.x

Komarraju, M., Msulkin, S., \& Bhattacharya, G. (2010). Role of student-faculty interaction in developing college students' academic self-concept, motivation, and achievement. Journal of College Student Development, 51(3), 332-342. https://doi.org/10.1353/csd.0.0137

Lambert, A., Terenzini, P., \& Lattuca, L. (2007). More than meets the eye: Curricular and programmatic effects on student learning. Research in Higher Education, 48, 141-168. https://doi.org/10.1007/s11162-006-9040-5

Loucks, H.D. (1976). Are physical education majors really fit? Journal of Physical Education and Recreation, $47(6), 36$. https://doi.org/10.1080/00971170.1976.10614218

Lovric, J., Prlic, N., Barac, I., Pluzaric, J., Puseljic, S., Berecki, I., \& Radic, R. (2014). Specificities and differences in nursing students' perceptions of nursing clinical faculties' competences. Journal of Professional Nursing, 30(5), 406-417. https://doi.org/10.1016/j.profnurs.2014.03.005

Pascarella, E. T., \& Terenzini, P. T. (2005). How college affects students. Vol. 2. A third decade of research. San Francisco: Jossey-Bass.

Puhl, R., Gold, J., Luedicke, J., \& DePierre, J. (2013). The effect of physicians' body weight on patient attitudes: implication for physician selection, trust and adherence to medical advice. International Journal of Obesity, 37(11), 1415-21. https://doi.org/10.1038/ijo.2013.33

Pratt, T., Cullen, F., Sellers, C. Winfree, L. Madensen, T., Daigle, Fearn, N., \& Gau, K. (2010) The empirical status of social learning theory: A meta-analysis, Justice Quarterly, 27(6), 765-802. https://doi.org/10.1080/07418820903379610 
Smith, D.R., \& Leggat, P. (2007). An international review of tobacco smoking in the medical profession: $1974-$ 2004. BMC Public Health, 7, 115. https://doi.org/10.1186/1471-2458-7-115

Sparling, P.B., \& Snow, T.K. (2002). Physical activity patterns in recent college alumni. Research Quarterly for Exercise and Sport,7(3):200-205. https://doi.org/10.1080/02701367.2002.10609009

Treadwell, I., \& Grobler, S. (2001). Students' perceptions on skills training in simulation. Medical Teacher, 23 (5), $476-$ 482. https://doi.org/10.1080/01421590120075715

Uttl, B., White, C., \& Gonzalez, D. (2017). Meta-analysis of faculty's teaching effectiveness: Student evaluation of teaching ratings and student learning are not related. Studies in Educational Evaluation, 54, 22-42. https://doi.org/10.1016/j.stueduc.2016.08.007

Zhu, D., Norman, I.J., While, A.E. (2011). The relationship between health professionals' weight status and attitudes towards weight management: A systematic review. Obesity Review, 12, e324-e337. https://doi.org/10.1111/j.1467-789x.2010.00841.x

Author Correspondence may be addressed to:

John Lothes II, LPA, Ed.D.

Lecturer

University of North Carolina Wilmington

School of Health and Applied Human Sciences

Physical Activity and Wellness (PED 101)

601 S. College Rd.

Wilmington, NC 28403

lothesj@uncw.edu

\section{Author's Note and Acknowledgements}

The author would like to thank Jessica Gaffney, Lindsey Nanney, and Jamie Updegraff for feedback on the process and design of this study. The author would also like to thank all the PED101 students that volunteered their time for this study. 


\section{APPENDIX A}

\section{Biographical Information}

Which PED 101 are you in (e.g. Swimming, BJJ, triathlon, etc)

Class Rank:

Sex:

Age:

Race/Ethnicity:

Student Perceptions of PED 101 Instructor's Behaviors:

please rate how seeing or finding out about some behaviors of your PED 101 instructor might effect your perceptions about them as a health expert.

1) Would seeing your PED 101 instructor smoking cigarettes effect how you feel about them as a health expert?

2) Does your PED 101 instructor being over-weight effect how you feel about them as a health expert?

3) Does your PED 101 instructor being of a healthy weight effect how you feel about them as a health expert?

4) Does your PED 101 instructor being underweight effect how you feel about them as a health expert?

5) How would seeing your PED 101 instructor eating fast food effect how you feel about them as a health expert?

6) How would seeing your PED 101 instructor drinking a beer, mixed drink or glass of wine out to dinner at a restaurant effect how you feel about them as a health expert?

7) How would seeing your PED 101 instructor drinking a beer, mixed drink or glass of wine at a bar effect how you feel about them as a health expert?

8) How would seeing your PED 101 instructor intoxicated at a bar (or restaurant) effect how you feel about them as a health expert?

9) How would finding out your PED 101 instructor smokes pot effect how you feel about them as a health expert?

10) How would seeing your PED 101 instructor drink water in class effect how you feel about them as a health expert?

11) How would seeing your PED 101 instructor drink soda/soft drinks (non-diet) in class effect how you feel about them as a health expert?

12) How would seeing your PED 101 instructor drink DIET soda/soft drinks in class effect how you feel about them as a health expert?

13) How would seeing your PED 101 instructor at the grocery store with a cart full off unhealthy (e.g high carb, high sugar) and processed food effect how you feel about them as a health expert?

14) How would seeing your PED 101 instructor at the grocery store with a cart full fruits, vegetables, proteins and healthy foods effect how you feel about them as a health expert?

15) How would seeing your PED 101 instructor at the rec center, other work out facilities (gold's gym, planet fitness, etc) or exercising on/off campus effect how you feel about them as a health expert?

16) Would hearing about your PED 101 instructor being vegetarian effect how you feel about them as a health expert?

17) Would hearing about your PED 101 instructor eating a protein heavy (chicken, fish, etc) diet effect how you feel about them as a health expert? 